\title{
Significance of Id-1 up-regulation and its association with EGFR in bladder cancer cell invasion
}

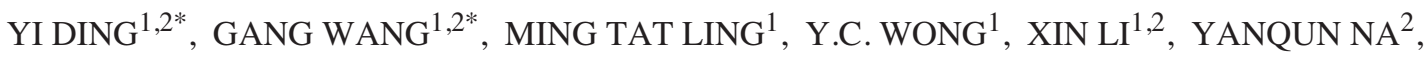 \\ XIAOMENG ZHANG ${ }^{1}$, CHEE WAI CHUA ${ }^{1}$, XIANGHONG WANG ${ }^{1}$ and DIANQI XIN ${ }^{2}$ \\ ${ }^{1}$ Cancer Biology Group, Department of Anatomy, Faculty of Medicine, University of Hong Kong, \\ Hong Kong; ${ }^{2}$ Peking University First Hospital, Institute of Urology, Beijing, P.R. China
}

Received October 24, 2005; Accepted December 2, 2005

\begin{abstract}
Epidermal growth factor receptor (EGFR) is suggested to be one of the positive factors in the invasive progression of bladder cancer. Id-1 (inhibitor of differentiation or DNA binding), a helix-loop-helix (HLH) transcription factor, was recently identified as a key factor in the EGFR signalling pathway. The aim of this study was to investigate the role of Id-1 in bladder cancer progression and its relationship with EGFR. Using clinical specimens from different stages of bladder cancer, immunohistochemical staining was performed to determine if Id-1 expression was positively associated with tumour staging and EGFR expression. The direct role of Id-1 in cancer cell invasion was also investigated through ectopically expressing the $I d-1$ gene in a RT112 bladder cancer cell line by wound closure and collagen invasion assays. To explore the therapeutic potential of targeting the $I d-1$ gene in the treatment of invasive bladder cancer, we studied if inactivation of the $I d-1$ gene through small RNA interference could lead to the suppression of invasion in a MGHU1 bladder cancer cell line. Our results showed that the up-regulation of Id-1 was associated with increased EGFR expression, clinical staging and the invasion ability of bladder cancer cells. Inactivation of Id-1 may be a potential therapeutic target to inhibit the invasion by bladder cancer cells.
\end{abstract}

Correspondence to: Dr Dianqi Xin, Peking University First Hospital, Institute of Urology, 8 Xishiku Str. Xicheng District, Beijing 100034, P.R. China

E-mail: xin-dinaqi@163.com

${ }^{*}$ Contributed equally

Abbreviations: EGFR, epidermal growth factor receptor; Id-1, inhibitor of differentiation/DNA binding; HLH, helix-loop-helix

Key words: inhibitor of differentiation/DNA binding, bladder cancer, epidermal growth factor receptor, invasion

\section{Introduction}

Bladder cancer is ranked as one of the top five most common cancers in Western countries such as the United Kingdom and United States. The majority of bladder cancers are superficial at presentation and do not show invasion of the detrusor muscle (i.e. stage Ta, T1 tumours), and the prognosis of this group of patients is relatively good with a 5-year survival rate of more than $70 \%$ (1). However, $20 \%$ of bladder cancer patients present with muscle invasive disease at diagnosis (i.e. T2-T4 tumours). If untreated, fewer than $15 \%$ of those patients will survive more than 2 years. Although the treatment of bladder cancer depends on tumour grading and staging, the majority of non-invasive tumours are treated by transurethral resection (TUR) with optional chemotherapy or immunotherapy. The current treatment options for invasive tumours are limited to radical cystectomy or radical radiotherapy, and the 5-year survival rate with either regimen is less than $40 \%(2,3)$. More than $50 \%$ of patients who undergo radical cystectomy will eventually present with recurrent distant disease, and it has been reported that neoadjuvant chemotherapy is beneficial to this group of patients. A study from a meta-analysis on more than 2500 patients from 11 clinical trials showed a $10 \%$ decrease in the mortality rate among bladder cancer patients treated with neoadjuvant chemotherapy (4). Two main challenges remain in the treatment of this cancer: i) to identify the small but significant number of patients with non-muscle-invasive disease who will progress to muscle invasive disease; and ii) to improve treatment regiments for muscle invasive bladder cancer (5).

Advances in molecular biology have led to the identification of several biological markers and therapeutic targets in bladder cancer, especially in invasive cancers. One such marker is the epidermal growth factor receptor (EGFR). Up-regulation of EGFR has been frequently reported in bladder cancer tissue samples (6-9). Several studies have positively correlated EGFR with tumour stage, tumour progression, and poor clinical outcome in bladder cancer patients $(7,8,10)$. It was reported that the ectopic expression of EGFR in SV40T transgenic mice not only enhanced tumour growth, but also promoted formation of high grade bladder carcinoma, indicating its role in the development and progression of this cancer (11). In addition, an in vitro study reported that the activation of EGFR in bladder cancer cell lines led to increased cell migration and invasion (12), as well as the activation of metalloproteinases, a group of 
zinc-dependent endopeptidases that have been positively associated with cancer metastasis $(12,13)$. These results suggest that the role of EGFR in tumour progression may be mediated through the direct promotion of the metastatic ability of bladder cancer cells. Furthermore, it was reported that treating bladder cancer cells with ZD1839 or Iressa, an orally active synthetic anilinoquinazoline and highly selective EGFR inhibitor, resulted in radiosensitisation to ionizing radiation, indicating that EGFR may be a potential therapeutic target in improving the treatment efficacy of bladder cancer (14).

Id-1 (inhibitor of differentiation or DNA binding) has been suggested to be one regulator of the EGFR pathway (15). Id-1 belongs to the helix-loop-helix (HLH) transcription factor family. It lacks the basic domain for DNA binding and acts as a dominant inhibitor of the basic HLH transcription factors by forming heterodimers (16). Like EGFR, up-regulation of Id-1 is frequently found in many types of human cancer such as breast (17), pancreas (18), cervical (19), head and neck (20), and prostate cancers (21). Increased Id-1 expression levels are associated with advanced tumour stage, as well as poor prognosis $(18,19,21)$. In addition, patients with higher levels of Id-1 have much a shorter overall survival than patients with relatively lower Id-1 expression in ovarian cancer (22). These results indicate that the overexpression of Id-1 may play an important role not only in tumourigenesis, but also in the progression of certain types of human cancer. The fact that ectopic expression of the $I d-1$ gene is able to promote both the proliferation and invasion by cancer cells suggests that it may be a key factor in promoting cancer cell growth and metastasis (23-25). In addition, evidence from our previous studies has shown that the Id-1-mediated cancer cell growth is associated with the activation of EGFR at both the transcriptional and protein level in prostate and ovarian cancer cells $(15,26)$. This indicates that the role of Id-1 on cancer cell growth may be regulated through its positive regulation of the EGFR signalling pathway. In this study, we investigated if the up-regulation of Id-1 played a role in the progression of bladder cancer and was associated with EGFR expression. First, we performed immunohistochemical staining on tissues derived from different stages of bladder cancer (Ta-T4) using antibodies against Id-1 and EGFR, and correlated the Id-1 expression levels with tumour staging and EGFR expression. Second, we studied the direct role of Id-1 on bladder cancer cell invasion by targeting the Id-1 gene in bladder cancer cell lines through the ectopic transfection of expression vectors. Our results showed that the up-regulation of Id-1 was associated with increased clinical staging of bladder cancer and the invasive ability of bladder cancer cells, and the positive role of Id-1 in bladder cancer invasion may be mediated through the EGFR signalling pathway. These lines of evidence suggest that Id-1 is a potential marker for invasive bladder cancer cells, and the inactivation of Id-1 is an effective therapeutic goal in the treatment of invasive bladder cancer.

\section{Materials and methods}

Cell lines and cell culture conditions. Human bladder cancer cel1 lines, RT112 and MGHU1, were kindly provided by Professor John R.M. Masters (Institute of Urology, University
College London, UK) and maintained in RPMI-1640 medium (Sigma, St. Louis, MO) supplemented with 5\% fetal calf serum and penicillin/streptomycin. To study the expression of Id-1, the cells were cultured in serum-free medium for at least $48 \mathrm{~h}$.

Tissue specimens. All of the formalin-fixed and paraffinembedded bladder cancer tissues were obtained from the Institute of Urology, Peking University. All tissues were obtained from transurethral resection (TUR) or radical cystectomy. The histopathology of the specimens was examined and classified by pathologists in the Department of Pathology at the same institution. All normal specimens $(n=5)$ showed no evidence of malignant cells. Bladder cancer specimens $(n=37)$ were taken from patients diagnosed with bladder cancer by histopathological examination, and divided into three groups: i) Ta+T1, tumours that have not invaded into the detrusor muscle $(n=15)$; ii) T2, tumours that have invaded into destrusor muscle $(\mathrm{n}=7)$; and iii) $\mathrm{T} 3+\mathrm{T} 4$, tumours that have invaded into perivesical tissues $(n=15)$.

Immunohistochemistry. Detailed experimental procedures were described previously (21). Briefly, paraffin-embedded tissues sectioned into a 5- $\mu \mathrm{m}$ thickness were deparaffinised in xylene and rehydrated in graded alcohols and distilled water. After antigen retrieval, endogenous peroxidase activity was blocked with $0.3 \%$ hydrogen peroxide in methanol for $30 \mathrm{~min}$, followed by rehydration in PBS and incubation with 5\% rabbit serum for $30 \mathrm{~min}$ to bind non-specific antigens. The slides were then incubated at $4{ }^{\circ} \mathrm{C}$ overnight with polyclonal antibodies against Id-1 or EGFR (Santa Cruz Biotechnology, Santa Cruz, CA, USA) in TBS containing $2 \%$ rabbit serum and $1 \%$ bovine serum albumin. This was followed by incubation with biotinylated anti-rabbit $\operatorname{IgG}$ at a dilution of 1:200 for $30 \mathrm{~min}$ at room temperature and then peroxidase-conjugated avidinbiotin complexes and 3,3'- diaminobenzidine (Dako, Glostrup, Denmark). The sections were counterstained with Mayer's haematoxylin and analysed by light microscopy. Sections were incubated with TBS containing $2 \%$ rabbit serum and $1 \%$ bovine serum albumin without primary antibody as negative controls.

Evaluation of Id-1 and EGFR immunostaining. Staining intensity (cytoplasmic staining for both proteins) was semiquantified in five randomly selected fields per tumour at a x400 magnification, and the intensity reading of each specimen was recorded. The staining intensity of each slide was scored as '-,' ‘+,' ‘++, or ' +++ ,' representing none, mild, moderate, or heavy staining, respectively. Specimens were then grouped according to stage (Ta-T4) and staining intensity. The percentages of samples with differential staining intensity were plotted against tumour staging.

Generation of Id-1 expressing stable transfectants. The pBabe-Id-1 retroviral expression vector and its corresponding vector control were used for the generation of stable transfectants in RT112 cells. Details on the vectors and transfection procedures have been described previously (25). The transfectant clones were selected and maintained in puromycin $(2 \mu \mathrm{g} / \mathrm{ml})$. Cell culture medium was changed to serum-free medium for $48 \mathrm{~h}$ before performing additional experiments. 


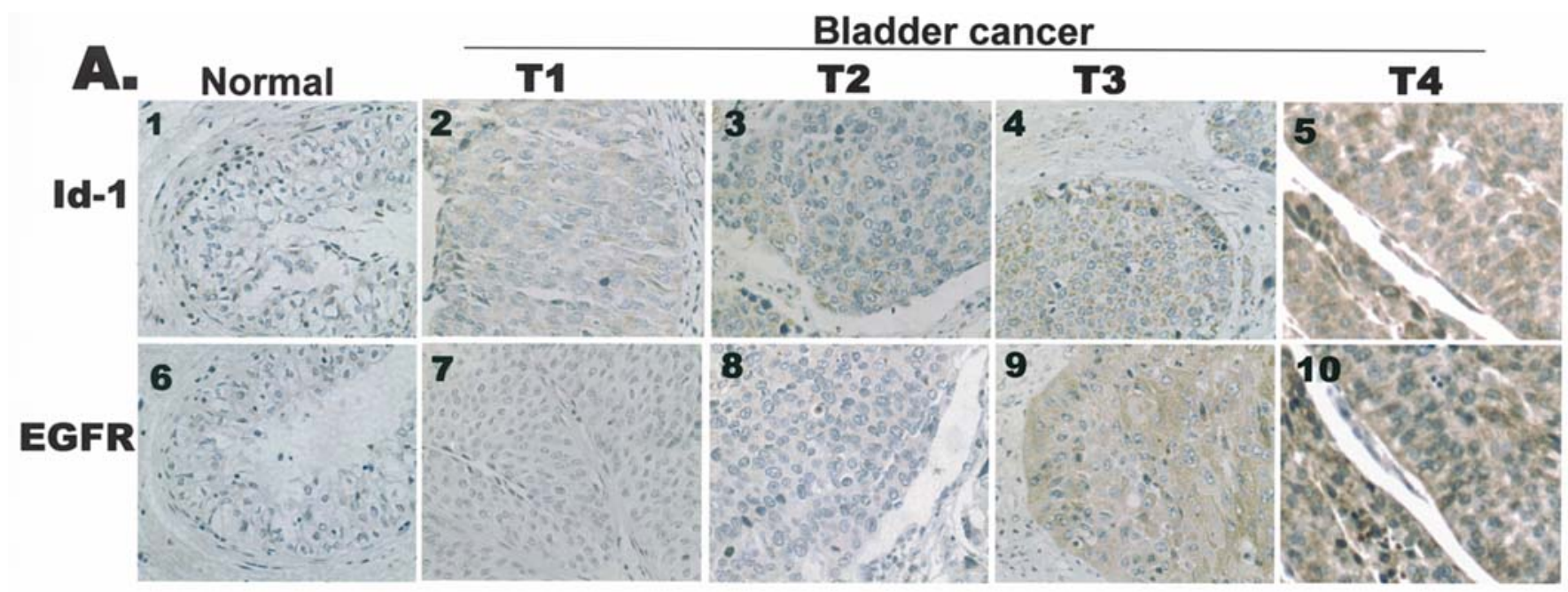

B. Id-1

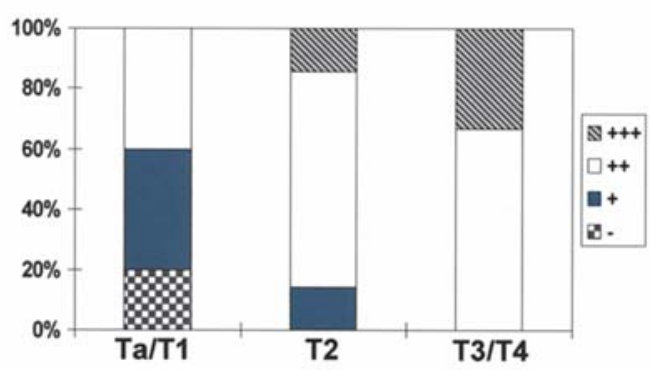

\section{EGFR}

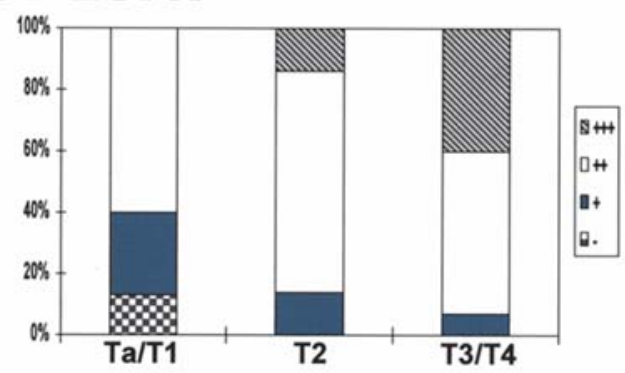

Figure 1. Expression of Id-1 and EGFR proteins in bladder cancer specimens. (A) Representative images of Id-1 (panels 1-5) and EGFR (panels 6-10) protein staining intensity in different stages of bladder cancer tissues and normal controls. Photos were taken under x400 magnification. (B and C) Semi-quantitative summary of Id-1 and EGFR staining intensity in different tumour stages. Note that increased Id-1 expression is associated with increased tumour staging and EGFR expression in bladder cancer specimens.

Construction of Si-RNA vectors and generation of stable si-Idl transfectants. The Id-1 Si-RNA vector was generated using the GeneSuppressor System kit according to the manufacturer's instructions (Imgenex, San Diego, CA, USA). Briefly, the primers containing the short hairpin RNA sequence targeting the $I d-1$ coding region were annealed and cloned into the pSuppressor-Retro vector to generate the si-RNA expression vector. The sequences of the si-Id-1 primers were: si-Id-1-F, TCG AGG CTG TTA CTC ACG CCT CAA GGA AGC TTG CTT GAG GCG TGA GTA ACA GCC TTT TT; and si-Id-1-R, CTA GAA AAA GGC TGT TAC TCA CGC CTC AAG CAA GCT TCC TTG AGG CGT GAG TAA CAG CC. The control vector was generated using the same procedures for the si-RNA vector except that the short hairpin RNA sequence was replaced with non-sense sequences that are not homologous to the human genome. The sequences of the control primers were: si-Con-F, TCG AGC GTA TTG CCT AGC ATT ACG TGA TGC TTG ACG TAA TGC TAG GCA ATA CGC TTT TT; and si-Con-R, CTA GAA AAA GCG TAT TGC CTA GCA TTS CGT CAA GCT TCA CGT AAT GCT AGG CAA TAC GC. The resulting vectors were transfected into the 293 packaging cell line using the Fugene 6 reagent. Retroviruses were collected 48 h later, mixed with polybrene $(8 \mu \mathrm{g} / \mathrm{ml})$, and then incubated with MGHU1 cells. Positive si-Id-1 clones were selected in neomycin $(600 \mu \mathrm{g} / \mathrm{ml})$, and a pool of stable transfectants was isolated after approximately 6 days of drug selection.
Luciferase assay. Cells were plated into a 12 -well plate at a density of $1 \times 10^{5}$ cells per well. After $24 \mathrm{~h}$, the medium was changed to SFM or $2.5 \%$ FCS medium. pER-1 (luciferase reporter containing the EGFR promoter; kindly provided by Dr A. Johnson, NCI, MD, USA) and pRL-CMV-Luc (internal control) were transfected into the cells using the Fugene 6 reagent (Roche Diagnostics, Indianapolis, IN). Cells were lysed $48 \mathrm{~h}$ after transfection and assayed for luciferase activity using the dual luciferase reporter assay system (Promega, WI, USA).

Western blot analysis. Detailed experimental procedures were described previously (25). Briefly, whole-cell lysate was prepared by resuspending the cell pellet in lysis buffer [50 mM Tris- $\mathrm{HCl}$ (pH 8.0), $150 \mathrm{mM} \mathrm{NaCl}, 1 \mathrm{mM}$ EDTA, $1 \%$ Triton $\mathrm{X}-100,2.5 \mathrm{mM}$ sodium pyrophosphate, $1 \mathrm{mM}$ $ß$-glycerophosphate, $1 \mathrm{mM} \mathrm{Na} \mathrm{VO}_{4}, 1 \mu \mathrm{g} / \mathrm{ml}$ aprotinin, $1 \mu \mathrm{g} / \mathrm{ml}$ leupeptin, and $1 \mathrm{mM}$ PMSF], and protein concentrations were measured using the Protein Assay kit (Bio-Rad, Hercules, CA, USA). Protein suspension from the whole-cell lysate (15-30 $\mu \mathrm{g}$ ) was loaded onto a sodium dodecylsulfatepolyacrylamide gel (SDS-PAGE) for electrophoresis and then transferred to a PVDF membrane (Amersham, Piscataway, NJ, USA). The membrane was then incubated with primary antibodies for 1-2 $\mathrm{h}$ at room temperature against Id-1, EGFR (Santa Cruz Biotechnology) or B-actin (Santa Cruz Biotechnology). After washing with TBS-T, the membrane 
was incubated with secondary antibody against mouse, rabbit or goat $\mathrm{IgG}$, and the signals were visualised using ECL and the Western blotting system (Amersham).

Wound closure assay. Cells $\left(10^{5}\right)$ were seeded into 6-well culture plates and allowed to grow to approximately $90-95 \%$ confluence in serum-free medium. Similar sized wounds were introduced to monolayer cells using a sterile yellow pipette tip. The speed of wound closure was monitored and photographed at the 24 and $48 \mathrm{~h}$ time points using a phasecontrast microscope under x100 magnification until complete wound closure was observed.

3-D collagen invasion assay. Detailed experimental procedures were published previously (27). Briefly, $200 \mu 1$ of cell suspension $\left(3 \times 10^{4}\right.$ cells $\left./ \mathrm{ml}\right)$ was mixed with $200 \mu 1$ of cold rat tail collagen, type I $(3.60 \mathrm{mg} / \mathrm{ml}$; BD Biosciences, MA, USA). The mixed cell solution was plated as droplets in a $60 \mathrm{~mm}$ Petri dish and air dried. RPMI-1640 medium containing $1 \%$ FCS was added to each dish containing the semi-solid collagen cell droplets. Cell morphology was observed daily under a phase-contrast microscope, and pictures were captured under x200 magnification after 5 days. A total of 500 colonies were counted in each experiment, and the percentage of colonies that consisted of elongated morphology was calculated. Each experiment was repeated at least 3 times, and error bars indicate the standard deviation.

Boyden chamber assay. The Boyden Chamber invasion assay was performed using a $6.4 \mathrm{~mm}$ diameter and $8.0 \mu \mathrm{m}$ pore size Transwell chamber (Milipore) coated with Matrigel (BectonDickinson) according to a previously published method (28). Briefly, $200 \mu \mathrm{l}$ of $0.1 \%$ BSA-RPMI-1640 containing $5 \times 10^{4}$ cells was added to the upper chamber, and $600 \mu 1$ invasion buffer (0.1\% BSA-RPMI-1640) containing fibronectin $(10 \mu \mathrm{g} / \mathrm{ml})$ and $600 \mu 15 \%$ FCS RPMI-1640 was added in the lower well as a chemoattractant. After incubating for $24 \mathrm{~h}$, the insert membranes were fixed and stained with Mayer's haematoxylin and $1 \% \mathrm{w} / \mathrm{v}$ aqueous eosin solution. The number of cells that migrated to the lower surface of the membrane was counted using a PC-based image-analysing system (Stereo Investigator, VT, USA), and data are presented as the mean of two wells from three experiments.

\section{Results}

Id-1 and EGFR expression in bladder cancer specimens. To study the association between Id-1 and bladder cancer staging, we examined Id-1 protein expression levels in three groups of bladder cancer tissues, Ta/T1 $(n=15), T 2(n=7)$, and T3/T4 $(n=15)$, and normal bladder tissues $(n=5)$ using immunohistochemistry. As shown in Fig. 1A (panels 1-5), Id-1 protein staining intensity was weak or undetectable in the normal bladder transitional epithelial cells (panel 1), while all of the cancer specimens showed positive Id-1 staining (panels 2-5). The Id-1 staining intensity was stronger with increased tumour staging, with the T4 tumours showing the highest Id-1 expression compared to the lower stage tumours. Semi-quantitation analysis showed that $100 \%$ of the T3/T4 tumours showed strong Id-1 staining (' ++ ' to ' +++ '), while
Table I. Summary of Id-1 expression in bladder cancer specimens.

\begin{tabular}{|c|c|c|c|c|c|}
\hline \multirow[b]{2}{*}{ Staging } & \multirow[b]{2}{*}{$\mathrm{n}$} & \multicolumn{4}{|c|}{ Staining intensity } \\
\hline & & - & + & ++ & $+++/++++$ \\
\hline $\mathrm{Ta} / \mathrm{T} 1$ & 15 & $3(20 \%)$ & $6(40.0 \%)$ & $6(40.0 \%)$ & $0(0 \%)$ \\
\hline $\mathrm{T} 2$ & 7 & $0(0 \%)$ & $1(14.3 \%)$ & $5(71.4 \%)$ & $1(14.3 \%)$ \\
\hline $\mathrm{T} 3+\mathrm{T} 4$ & 15 & $0(0 \%)$ & $0(0 \%)$ & $10(66.7 \%)$ & $5(33.3 \%)$ \\
\hline
\end{tabular}
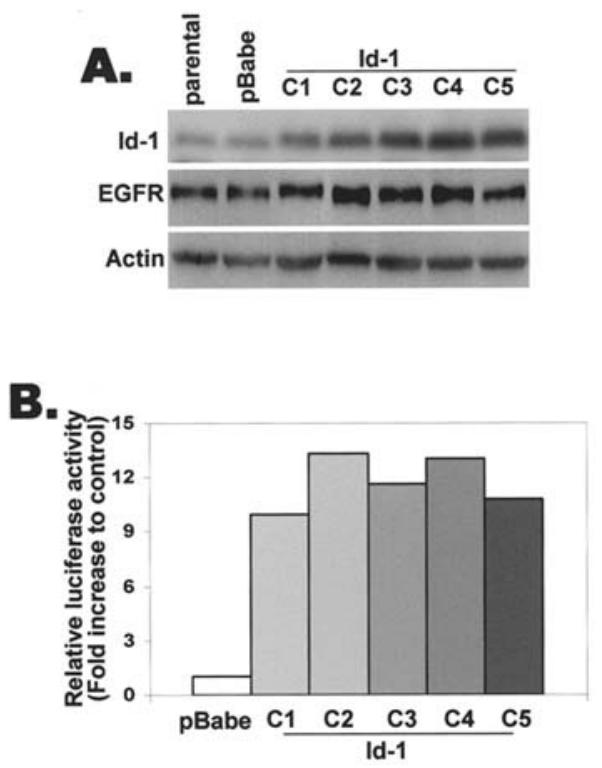

Figure 2. Ectopic Id-1 expression in bladder cancer cells and its association with EGFR expression. An Id-1 expression vector was transfected into RT112 cells, and five stable transfectant clones were generated. (A) Western blot analysis of differential Id-1 and EGFR between the Id-1 transfectants (C1-C5), vector control (pBabe), and parent cells (parental). (B) Relative EGFR luciferase activity in the cells with high and low levels of Id-1. Note that ectopic Id-1 expression leads to increased EGFR expression and its promoter activity in the Id-1 transfectants.

Table II. Summary of EGFR expression in bladder cancer specimens.

\begin{tabular}{|c|c|c|c|c|c|}
\hline \multirow[b]{2}{*}{ Staging } & \multirow[b]{2}{*}{$\mathrm{n}$} & \multicolumn{4}{|c|}{ Staining intensity } \\
\hline & & - & + & ++ & $+++/++++$ \\
\hline $\mathrm{Ta} / \mathrm{T} 1$ & 15 & $2(13.3 \%)$ & $4(26.6 \%)$ & $9(60.0 \%)$ & $0(0 \%)$ \\
\hline $\mathrm{T} 2$ & 7 & $0(0 \%)$ & $1(14.3 \%)$ & $5(71.4 \%)$ & $1(14.3 \%)$ \\
\hline $\mathrm{T} 3+\mathrm{T} 4$ & 15 & $0(0 \%)$ & $1(6.7 \%)$ & $8(53.3 \%)$ & $6(40.0 \%)$ \\
\hline
\end{tabular}

the majority of Ta/T1 tumours $(60 \%)$ showed an Id-1 intensity of '+' or less (Fig. 1B and Table I). These results demonstrate that the up-regulation of Id-1 is associated with increased bladder cancer staging, indicating that Id-1 may play a positive role in the invasion ability of bladder cancer cells.

As discussed previously, EGFR has been indicated as a key factor in promoting bladder cancer progression, and the up-regulation of EGFR has been positively correlated with high tumour stage and poor clinical outcome in bladder cancer patients $(7,8,10)$. We found that the overexpression of Id-1 in certain types of human cancer cells led to the activation 

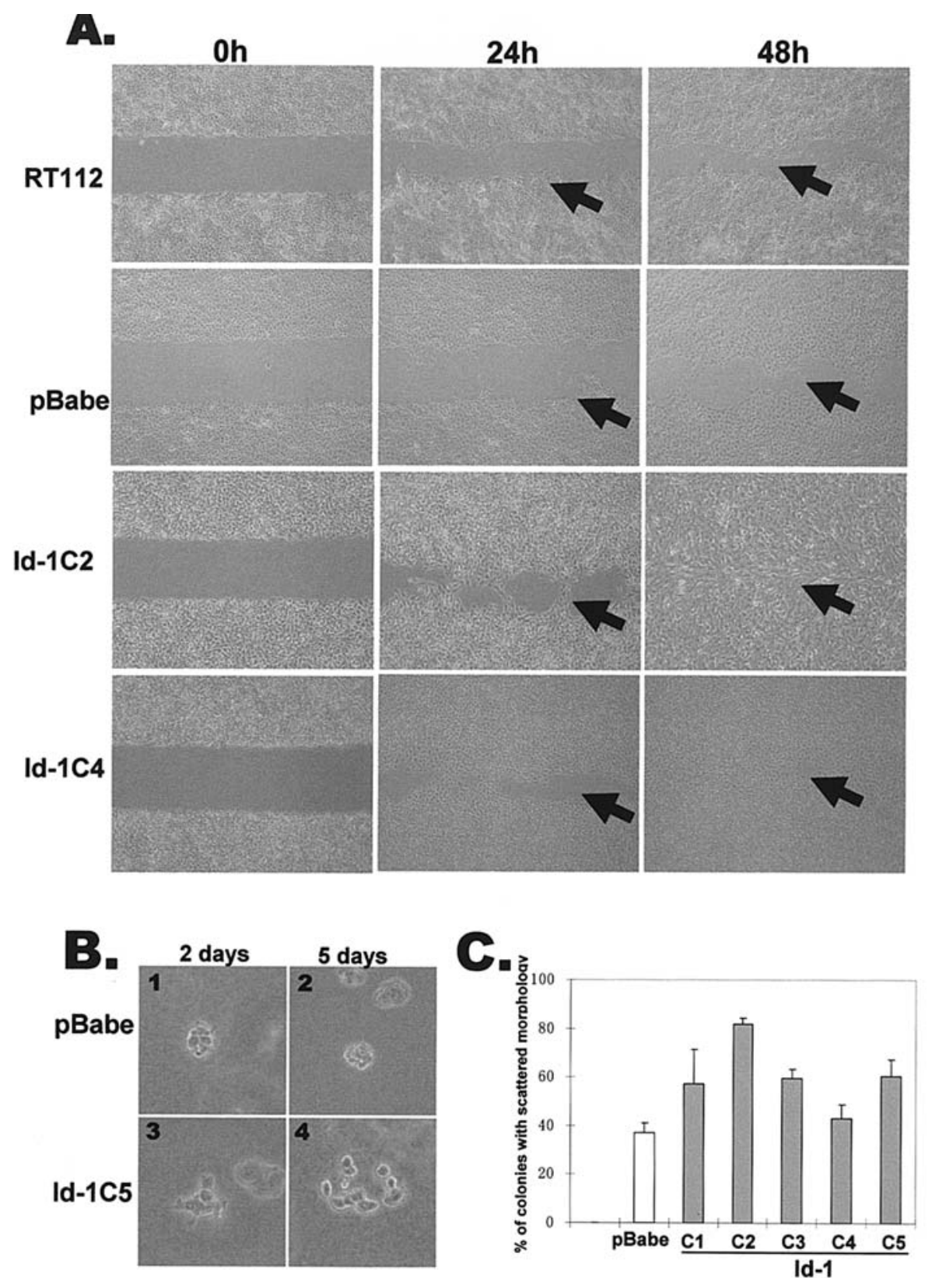

Figure 3. Effect of Id-1 overexpression on bladder cancer cell migration and invasion. (A) Differential migration rate between the Id-1 transfectants and controls, as determined by wound closure assay. A similar sized wound was introduced in confluent monolayer cells, and cell migration rate was monitored at indicated time points. Note that overexpression of Id-1 leads to an increased cell migration rate (see arrows). (B and C) Evidence of Id-1-induced invasive growth. Single cell suspension was cultured in 3-D collagen gel, and photos were taken at the indicated time points. (B) Representative photos of colonies formed in 3-D collagen gel. Note that cells with high levels of Id-1 show invasive growth in collagen gel. (C) Quantitative analysis of the colonies, with scattered morphology in the cells with high and low levels of Id-1 expression.

of EGFR $(15,26)$. To further confirm the significance of Id-1 up-regulation in bladder cancer invasion and investigate the association between Id-1 and EGFR in bladder cancer cells, we examined EGFR expression in the same specimens. Similar to the Id-1 staining patterns, the EGFR staining intensity was also increased with increased staging (Fig. 1A, panels 6-10). The expression of EGFR was highest in T4 tumours, which is consistent with previous reports $(10,29)$. A semi-quantitative analysis on the expression of Id-1 and EGFR revealed that the majority of high stage tumours (T2-T4) showed both the highest Id-1 and EGFR expression compared to the $\mathrm{Ta} / \mathrm{T} 1$ tumours, indicating that increased Id-1 expression is associated with up-regulation of EGFR in high stage bladder cancer cells (Figs. 1B and C, and Tables I and II).
Effect of ectopic Id-1 expression on EGFR expression and invasion ability of bladder cancer cells. To further study the role of Id-1 in bladder cancer cell invasion, we transfected an Id- 1 expression vector into an RT112 bladder cancer cell line, which showed low levels of Id-1 protein under serum-free conditions in culture (25). As shown in Fig. 2A, five stable Id-1 transfectant clones ( $\mathrm{C} 1$ to $\mathrm{C} 5$ ) were generated that showed an up to 5-fold increase in Id-1 protein expression compared to the parental line and vector control pBabe cells. EGFR protein levels were also higher in the cells expressing high levels of Id-1 protein. Furthermore, luciferase assay showed that EGFR promoter activity was increased in the Id-1 transfectants (Fig. 2B), suggesting that the overexpression of Id-1 may be able to activate EGFR at the transcription level. These results 

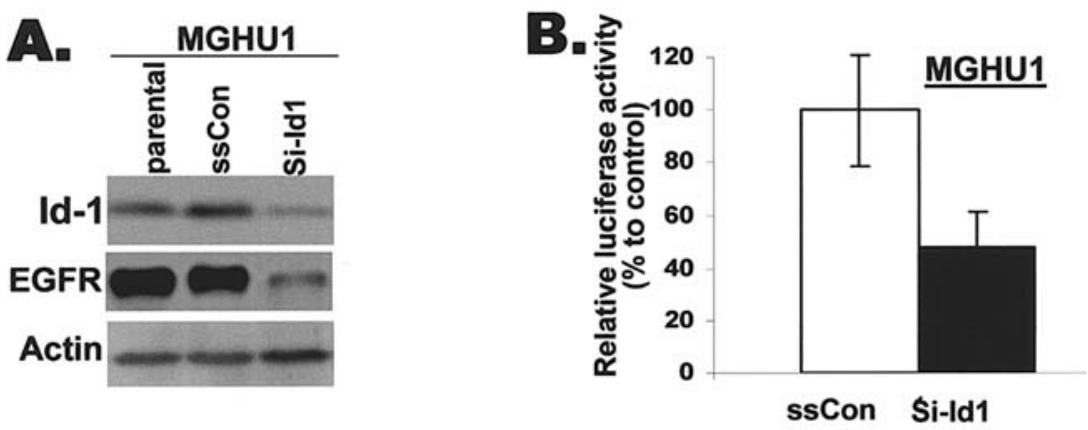

Figure 4. Inactivation of Id-1 in bladder cancer cells and its effect on EGFR expression. An expression vector containing a si-Id-1 sequence was transfected into MGHU1 cells, and a pool of stable transfectants (Si-Id-1) and vector control cells (ssCon) was generated. (A) Western blot analysis of Id-1 and EGFR expression. Note that decreased Id-1 and EGFR protein expression is shown in the Si-Id-1 transfectants. (B) Relative EGFR luciferase activity in the cells with high and low levels of Id-1. Note that EGFR luciferase activity is decreased in the si-Id-1 transfectants.

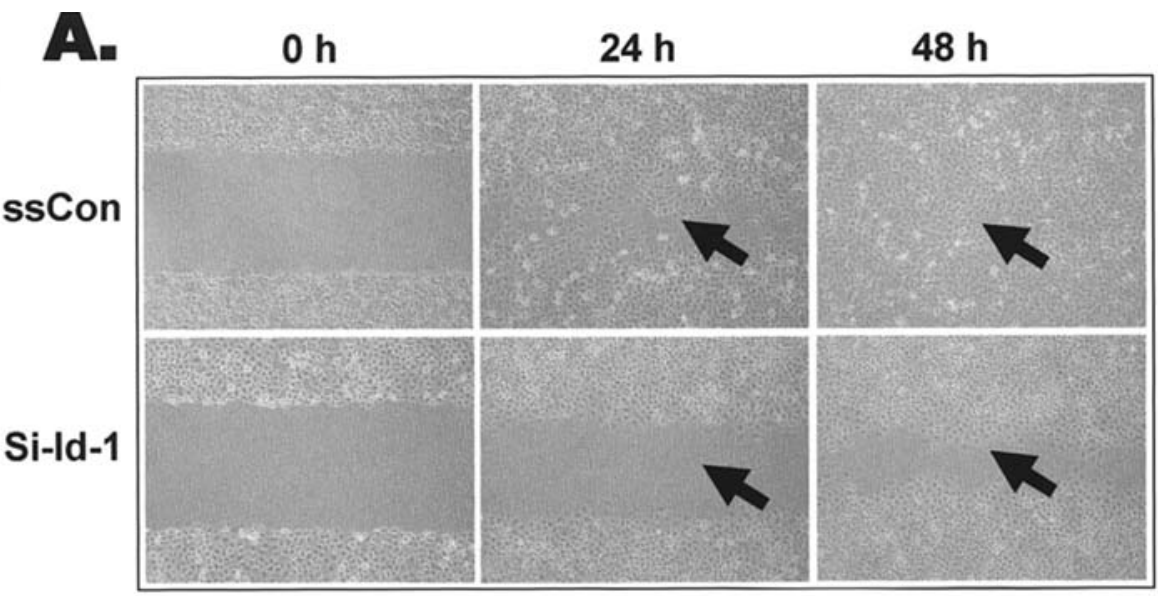

\section{B}
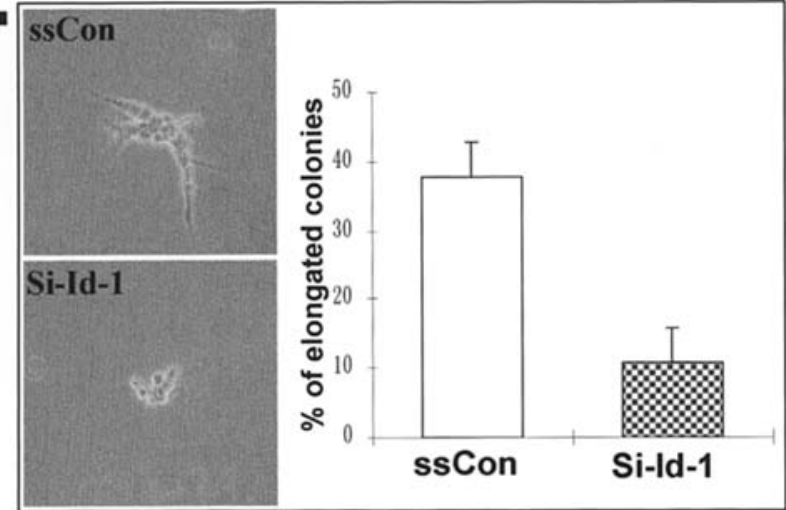

C.

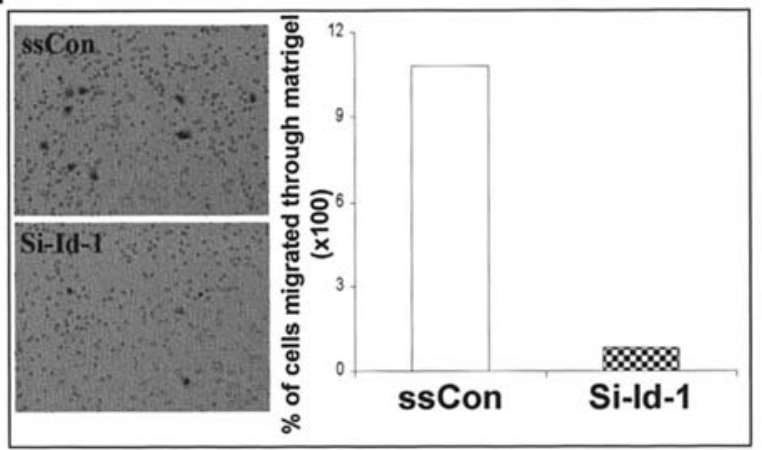

Figure 5. Effect of Id-1 inactivation on bladder cancer cell migration and invasion. (A) Representative photos of wound closure assay. Note that the migration rate is reduced in the Si-Id-1 cells. (B) Representative photos and summary of 3-D collagen assay. Note that the penetration ability of MGU1 cells is suppressed in Si-Id-1 transfectants. (C) Boyden Chamber invasion assay. Note that the number of cells that migrated through Boyden Chamber is much lower in the Si-Id-1 transfectants.

showed that the overexpression of Id-1 in bladder cancer cells resulted in the up-regulation of EGFR, which further confirms the immunostaining results on bladder cancer specimens.

To investigate if increased Id- 1 expression in bladder cancer cells could promote cell invasion, we first performed wound closure assay to test the migration ability in cells expressing high and low levels of Id-1. As shown in Fig. 3A, we found that the migration speed of the Id-1 transfectants was much faster than the parental and vector control cells (see arrows). While there was an open wound in the control cells (RT112 and pBabe) after $24 \mathrm{~h}$ wound induction, a large number of Id-1 transfectants had already migrated into the open wound area. By $48 \mathrm{~h}$, the wound was completely closed by migrating cells in the Id-1 transfectants, but still wide open in the control cells. These results indicate that the upregulation of Id-1 leads to promoting migration in bladder cancer cells. To further confirm these results, we performed a 3-D collagen invasion assay to examine the ability of cancer cells to invade semi-solid collagen gel in culture. While the vector control cells grew in packed colonies in the collagen gel (panels 1 and 2), which indicates a deficiency in invasive growth, the Id-1 transfectants grew into the semi-solid 
collagen and formed scattered colonies (panels 3 and 4), which suggests their ability to invade the extracellular matrix (Fig. 3C). Semi-quantitative analysis showed that a much higher percentage of Id-1-transfected cells showed scattered morphology (up to $80 \%$ ) compared to the vector control (up to $40 \%$ ) (Fig. 3C). These results indicate that the overexpression of Id-1 leads to increased invasion by bladder cancer cells.

Inhibitory effect of Id-1 inactivation on EGFR expression and bladder cancer cell invasion. We next studied the direct effect of Id-1 on the invasion ability of bladder cancer cells and investigated if the inactivation of Id-1 could lead to the suppression of bladder cancer cell invasion. A pSuppressorRetro expression vector containing a small RNA sequence targeting the $I d-1$ gene (Si-Id-1) was transfected into an MGHU1 bladder cancer cell line, which showed constant Id-1 protein expression under serum-free culture conditions. As shown in Fig. 4A, transfection of the Si-Id-1 vector resulted in decreased Id-1 protein levels in MGHU1 cells compared to the vector control (ssCon) and parental cells. In addition, expression of the EGFR protein (Fig. 4A) and its promoter activity (Fig. 4B) were also significantly decreased in the Si-Id-1 transfectants. These results further indicate a positive association between Id-1 and EGFR.

Wound closure assay showed that the migration ability of Si-Id-1 transfectants was much slower than the vector control (Fig. 5A, arrows). In addition, the invasion ability of Si-Id-1 transfectants was also reduced. While the ssCon cells grew in collagen gels and formed elongated colonies, the cells with low levels of Id-1 lost the ability to penetrate the semi-solid collagen gel and formed tightly packed colonies (Fig. 5B). A semiquantitative analysis showed that just over $10 \%$ of the Si-Id-1 transfectants displayed elongated morphology in collagen gels compared to $40 \%$ of the vector control cells. To further confirm these results, we performed a Boyden Chamber assay, which tests the invasive ability of a cell through a Matrigel filter. While more than $10 \%$ of the vector control cells migrated through the Matrigel filter in a 12-h period, approximately $2 \%$ of the Si-Id-1 cells were able to penetrate the filter membrane (Fig. 5C). These results demonstrate that the inhibition of Id-1 expression in bladder cancer cells resulted in the suppression of their invasion and migration abilities.

\section{Discussion}

In this study, we demonstrated that increased Id-1 expression was associated with increased clinical staging in bladder cancer specimens (Fig. 1 and Table I). In addition, we showed that the up-regulation of Id-1 by ectopically expressing the $I d-1$ gene in bladder cancer cells led to the promotion of both invasion and migration (Figs. 2 and 3). In contrast, the downregulation of Id-1 by small RNA interference resulted in the suppression of bladder cancer invasion. These results identified a novel key factor in the progression of bladder cancer and suggested a potential therapeutic target in the treatment of invasive bladder cancer. Furthermore, evidence that the upregulation of Id-1 was associated with increased EGFR expression in the bladder cancer specimens and Id-1 transfectants suggests that the Id-1-mediated bladder cancer invasion may be regulated through the EGFR signalling pathway. EGFR-based therapy has shown promising results in certain cancers (30), and our results may provide an alternative therapeutic target for the EGFR signalling pathway in the treatment of human cancer.

As discussed previously, the up-regulation of Id-1 has been reported in many types of human cancer, and its expression levels are positively associated with the clinical progression of several types of human cancer (31). In this study, we provide the first evidence demonstrating a positive role of Id-1 in the metastatic progression of bladder cancer. We found that a high percentage of early stage bladder cancer specimens (Ta/T1, 60\%) showed weak Id-1 staining (estimated as $\leq+$ '), while the majority of high stage tumours (T2-T4, $85-100 \%$ ) showed strong Id-1 staining (estimated as $\geq$ '++') (Fig. 1 and Table I). These results suggest that increased Id-1 expression is associated with the increased invasive potential of bladder cancer cells. This hypothesis is supported by in vitro studies on RT112 and MGH1 bladder cancer cell lines, which showed that ectopic expression of the $I d-1$ gene led to the promotion of invasion, while the down-regulation of Id-1 resulted in the suppression of bladder cancer cell invasion and migration (Figs. 2-5). These results further indicate that the presence of high levels of the Id-1 protein in bladder cancer cells may provide an advantage for invasive growth. However, we also observed that $40 \%$ of early stage tumours showed relatively high levels of Id-1 expression (Fig. 1B and Table I). Although further follow-up studies are required, it is possible that this group of patients may have the potential to progress to invasive tumours. We are in the process of confirming this hypothesis using a larger number of tissue samples. This hypothesis is also supported by evidence generated from both the current study and previous reports that the overexpression of Id-1 is associated with increased cell invasion and migration (Figs. 2 and 3) (32). The down-regulation of Id-1 in a breast cancer animal model leads to decreased metastatic ability of xenografts and reduced invasion ability in cultured cells (23). Id-1 is also reported to induce angiogenesis, which is essential for metastatic growth, and this process may be mediated through the activation of the vascular endothelial growth factor (VEGF). Other studies showed that inactivation of Id-1 leads to the down-regulation of VEGF in support of this hypothesis $(33,34)$. In the present study, we also demonstrated that the down-regulation of Id-1 by small RNA technology led to the suppression of cancer cell invasion and migration, implicating Id-1 as a potential therapeutic target in controlling the progression of bladder cancer to an invasive stage.

Since EGFR expression is associated with tumour invasion, poor prognosis, and poor response to clinical treatment in bladder cancer patients $(6-10,29)$, targeting the EGFR pathway may be a way of improving the current treatment efficacy EGFR-based therapy using anti-EGFR monoclonal antibodies (35) or small molecule EGFR tyrosine kinase inhibitors such as ZD1839 or Iressa (36) has shown promising results in several clinical trials either alone or in combination with chemotherapeutic drugs (30). In addition, ZD1839 is reported to be a radiosensitiser on bladder cancer cells (14). In this study, the results showed that the up-regulation of EGFR was associated with the overexpression of Id- 1 in bladder cancer cells, and tissue specimens suggest that Id-1 may be a key 
factor in the EGFR signalling pathway. This hypothesis is supported by evidence generated from previous studies that the overexpression of Id-1 is able to induce EGFR expression at both the transcriptional and protein level, while the inactivation of Id-1 leads to the suppression of EGFR expression in prostate and ovarian cancer cells $(15,26)$. Results of the current study further support Id-1 as a key regulator of the EGFR signalling pathway, and provide an additional therapeutic target of the EGFR signalling pathway in bladder cancer.

In summary, we demonstrated a potential biomarker for the identification of invasive bladder cancer cells. In addition, our results suggest that the down-regulation of Id-1 could be a potential target for inhibiting the invasion by bladder cancer cells and may also be an alternative scheme to inactivate the EGFR signalling pathway.

\section{References}

1. Fitzpatrick JM, West AB, Butler MR, Lane V and O'Flynn JD: Superficial bladder tumors (stage pTa, grades 1 and 2): the importance of recurrence pattern following initial resection. $\mathbf{J}$ Urol 135: 920-922, 1986.

2. Pearse HD, Reed RR and Hodges CV: Radical cystectomy for bladder cancer. J Urol 119: 216-218, 1978.

3. Gospodarowicz MK, Hawkins NV, Rawlings GA, Connolly JG, et al: Radical radiotherapy for muscle invasive transitional cell carcinoma of the bladder: failure analysis. J Urol 142: 1448-1453, 1989.

4. Winquist E, Kirchner TS, Segal R, Chin J and Lukka H: Neoadjuvant chemotherapy for transitional cell carcinoma of the bladder: a systematic review and meta-analysis. J Urol 171: 561-569, 2004.

5. Colquhoun AJ and Mellon JK: Epidermal growth factor receptor and bladder cancer. Postgrad Med J 78: 584-589, 2002.

6. Neal DE, Marsh C, Bennett MK, Abel PD, Hall RR, Sainsbury JR and Harris AL: Epidermal-growth-factor receptors in human bladder cancer: comparison of invasive and superficial tumours. Lancet 1: 366-368, 1985.

7. Neal DE, Sharples L, Smith K, Fennelly J, Hall RR and Harris AL: The epidermal growth factor receptor and the prognosis of bladder cancer. Cancer 65: 1619-1625, 1990.

8. Mellon K, Wright C, Kelly P, Horne CH and Neal DE: Longterm outcome related to epidermal growth factor receptor status in bladder cancer. J Urol 153: 919-925, 1995.

9. Chow NH, Liu HS, Lee EI, Chang CJ, Chan SH, Cheng HL, Tzai TS and Lin JS: Significance of urinary epidermal growth factor and its receptor expression in human bladder cancer. Anticancer Res 17: 1293-1296, 1997.

10. Nguyen PL, Swanson PE, Jaszcz W, Aeppli DM, Zhang G, Singleton TP, Ward S, Dykoski D, Harvey J and Niehans GA: Expression of epidermal growth factor receptor in invasive transitional cell carcinoma of the urinary bladder. A multivariate survival analysis. Am J Clin Pathol 101: 166-176, 1994.

11. Cheng J, Huang H, Zhang ZT, Shapiro E, Pellicer A, Sun TT and Wu XR: Overexpression of epidermal growth factor receptor in urothelium elicits urothelial hyperplasia and promotes bladder tumor growth. Cancer Res 62: 4157-4163, 2002.

12. Schafer B, Gschwind A and Ullrich A: Multiple G-proteincoupled receptor signals converge on the epidermal growth factor receptor to promote migration and invasion. Oncogene 23: 991-999, 2004.

13. Chambers AF and Matrisian LM: Changing views of the role of matrix metalloproteinases in metastasis. J Natl Cancer Inst 89: 1260-1270, 1997.

14. Maddineni SB, Sangar VK, Hendry JH, Margison GP and Clarke NW: Differential radiosensitisation by ZD1839 (Iressa), a highly selective epidermal growth factor receptor tyrosine kinase inhibitor in two related bladder cancer cell lines. Br J Cancer 92: 125-130, 2005.

15. Ling MT, Wang X, Lee DT, Tam PC, Tsao SW and Wong YC: Id-1 expression induces androgen-independent prostate cancer cell growth through activation of epidermal growth factor receptor (EGF-R). Carcinogenesis 25: 517-525, 2004.
16. Benezra R, Davis RL, Lockshon D, Turner DL and Weintraub H: The protein Id: a negative regulator of helix-loop-helix DNA binding proteins. Cell 61: 49-59, 1990.

17. Lin CQ, Singh J, Murata K, Itahana Y, Parrinello S, Liang SH, Gillett CE, Campisi J and Desprez PY: A role for Id-1 in the aggressive phenotype and steroid hormone response of human breast cancer cells. Cancer Res 60: 1332-1340, 2000.

18. Maruyama H, Kleeff J, Wildi S, Friess H, Buchler MW, Israel MA and Korc M: Id-1 and Id-2 are overexpressed in pancreatic cancer and in dysplastic lesions in chronic pancreatitis. Am J Pathol 155: 815-822, 1999.

19. Schindl M, Oberhuber G, Obermair A, Schoppmann SF, Karner B and Birner P: Overexpression of Id-1 protein is a marker for unfavorable prognosis in early-stage cervical cancer. Cancer Res 61: 5703-5706, 2001

20. Langlands K, Down GA and Kealey T: Id proteins are dynamically expressed in normal epidermis and dysregulated in squamous cell carcinoma. Cancer Res 60: 5929-5933, 2000.

21. Ouyang XS, Wang X, Lee DT, Tsao SW and Wong YC: Overexpression of ID-1 in prostate cancer. J Urol 167: 2598-2602, 2002.

22. Schindl M, Schoppmann SF, Strobel T, Heinzl H, Leisser C, Horvat R and Birner P: Level of Id-1 protein expression correlates with poor differentiation, enhanced malignant potential, and more aggressive clinical behavior of epithelial ovarian tumors. Clin Cancer Res 9: 779-785, 2003.

23. Fong S, Itahana Y, Sumida T, Singh J, Coppe JP, Liu Y, Richards PC, Bennington JL, Lee NM, Debs RJ and Desprez PY: Id-1 as a molecular target in therapy for breast cancer cell invasion and metastasis. Proc Natl Acad Sci USA 100: 13543-13548, 2003.

24. Ling MT, Wang X, Ouyang XS, Lee TK, Fan TY, Xu K, Tsao SW and Wong YC: Activation of MAPK signaling pathway is essential for Id-1 induced serum-independent prostate cancer cell growth. Oncogene 21: 8498-8505, 2002.

25. Ouyang XS, Wang X, Ling MT, Wong HL, Tsao SW and Wong YC: Id-1 stimulates serum-independent prostate cancer cell proliferation through inactivation of $\mathrm{p} 16(\mathrm{INK} 4 \mathrm{a}) / \mathrm{pRB}$ pathway. Carcinogenesis 23: 721-725, 2002.

26. Zhang X, Ling MT, Feng H, Wong YC, Tsao SW and Wang X: Id-I stimulates cell proliferation through activation of EGFR in ovarian cancer cells. Br J Cancer 91: 2042-2047, 2004.

27. Chun Z: M-TLTK-WLKMXWaY-CW. FTY720, a fungus metabolite, inhibits invasion ability of androgen-independent prostate cancer cells through inactivation of RhoA-GTPase. Cancer Lett 2005.

28. Lo AK, Liu Y, Wang XH, Huang DP, Yuen PW, Wong YC and Tsao GS: Alterations of biologic properties and gene expression in nasopharyngeal epithelial cells by the Epstein-Barr virusencoded latent membrane protein 1. Lab Invest 83: 697-709, 2003.

29. Bue P, Wester K, Sjostrom A, Holmberg A, Nilsson S, Carlsson J, Westlin JE, Busch C and Malmstrom PU: Expression of epidermal growth factor receptor in urinary bladder cancer metastases. Int J Cancer 76: 189-193, 1998.

30. Baselga J, Pfister D, Cooper MR, Cohen R, Burtness B, Bos M, D'Andrea G, Seidman A, Norton L, Gunnett K, Falcey J, Anderson V, Waksal $\mathrm{H}$ and Mendelsohn J: Phase I studies of anti-epidermal growth factor receptor chimeric antibody C225 alone and in combination with cisplatin. J Clin Oncol 18: 904-914, 2000 .

31. Wong YC, Wang X and Ling MT: Id-1 expression and cell survival. Apoptosis 9: 279-289, 2004.

32. Desprez PY, Lin CQ, Thomasset N, Sympson CJ, Bissell MJ and Campisi J: A novel pathway for mammary epithelial cell invasion induced by the helix-loop-helix protein Id-1. Mol Cell Biol 18: 4577-4588, 1998.

33. Ling MT, Lau TC, Zhou C, Chua CW, Kwok WK, Wang X and Wong YC: Overexpression of Id-1 in prostate cancer cells promotes angiogenesis through activation of vascular endothelial growth factor (VEGF). Carcinogenesis (In press).

34. Lyden D, Young AZ, Zagzag D, Yan W, Gerald W, O'Reilly R, Bader BL, Hynes RO, Zhuang Y, Manova K and Benezra R: Id1 and Id3 are required for neurogenesis, angiogenesis and vascularization of tumour xenografts. Nature 401: 670-677, 1999.

35. Herbst RS and Shin DM: Monoclonal antibodies to target epidermal growth factor receptor-positive tumors: a new paradigm for cancer therapy. Cancer 94: 1593-1611, 2002.

36. Albanell J, Rojo F and Baselga J: Pharmacodynamic studies with the epidermal growth factor receptor tyrosine kinase inhibitor ZD1839. Semin Oncol 28: 56-66, 2001. 